\title{
Efficacy and Safety of Baclofen for Alcohol Dependence: A Randomized, Double-Blind, Placebo-Controlled Trial
}

\author{
James C Garbutt, M.D., Alexei B Kampov-Polevoy, M.D., Ph.D., Robert Gallop, Ph.D., Linda \\ Kalka-Juhl, and Barbara A. Flannery, Ph.D. \\ Department of Psychiatry and the Bowles Center for Alcohol Studies, University of North Carolina \\ at Chapel Hill, Chapel Hill, North Carolina (JCG, ABKP, LKJ, BAF); Research Triangle \\ International, Baltimore, Maryland (BAF); West Chester University, West Chester, Pennsylvania
} $(\mathrm{RG})$

\begin{abstract}
Background-Recent clinical trials and case-reports indicate that baclofen, a GABA $\mathrm{B}$ agonist, may have efficacy for alcohol dependence. Baclofen has been shown to enhance abstinence, to reduce drinking quantity, to reduce craving, and to reduce anxiety in alcohol dependent individuals in two placebo-controlled trials in Italy. However, the clinical trial data with baclofen is limited. The purpose of the present study was to test the efficacy and tolerability of baclofen in alcohol dependence in the United States.
\end{abstract}

Methods-The study was a double-blind, placebo-controlled, randomized study comparing 30 $\mathrm{mg}$ per day of baclofen to placebo over 12 weeks of treatment and utilizing eight sessions of BRENDA, a low-intensity psychosocial intervention. 121 subjects were screened to yield 80 randomized subjects (44 male) with randomization balanced for gender. Percent heavy drinking days was the primary outcome measure with other drinking outcomes, anxiety levels, and craving as secondary outcomes. Tolerability was examined.

Results-76\% of subjects completed the study. No difference by drug condition was seen in $\%$ heavy drinking days where on-average rates were $25.5 \%( \pm 23.6 \%)$ for placebo and $25.9 \%( \pm$ $23.2 \%)$ for baclofen during treatment $(\mathrm{t}(73)=0.59, \mathrm{p}=0.56)$. Similarly, no differences were seen by drug condition in \% days abstinent, time to first drink, or time to relapse to heavy drinking. Baclofen was associated with a significant reduction in state anxiety $(\mathrm{F}(1,73)=5.39, \mathrm{p}=0.02)$. Baclofen was well tolerated with only two individuals stopping baclofen because of adverse events. There were no serious adverse events.

Conclusions-Baclofen, a $\mathrm{GABA}_{\mathrm{B}}$ agonist, represents a possible new pharmacotherapeutic approach to alcohol dependence. Despite encouraging preclinical data and prior positive clinical trials with baclofen in Italy, the current trial did not find evidence that baclofen is superior to placebo in the treatment of alcohol dependence. Additional clinical trial work is necessary to establish whether baclofen does or does not have therapeutic efficacy in alcohol dependence and, if it does, what factors are predictive of response.

\section{Keywords}

baclofen; alcoholism; placebo-controlled trial

Corresponding Author: James C. Garbutt, M.D., Department of Psychiatry, CB\#7160, University of North Carolina at Chapel Hill, Chapel Hill, North Carolina, 27599-7160; fax 919-966-5628; phone 919-966-4652; jc_garbutt@med.unc.edu. 


\section{Introduction}

The $\mathrm{GABA}_{\mathrm{B}}$ receptor agonist, baclofen, has been used for decades as an anti-spasticity medication to treat a number of neurological disorders. Recently, alcohol and other drug researchers have examined baclofen in relation to various components of alcohol and drug self-administration and withdrawal at the preclinical (e.g., Colombo et al., 2002; File et al., 1991; Knapp et al., 2007; Walker and Koob, 2007) and clinical level (Addolorato et al., 2000; Addolorato et al., 2002; Addolorato et al., 2007; Flannery et al., 2004). In aggregate, the animal and human findings suggest that baclofen may have value for the treatment of alcohol dependence but highlight the need for additional clinical trials.

Preclinical studies have reported that baclofen can reduce levels of alcohol consumption in rats trained to prefer alcohol (Daoust et al., 1987) or in rats that have been made physically dependent on alcohol using a vapor chamber (Walker and Koob, 2007). Baclofen has been found to suppress the motivation to consume alcohol as measured using an extinction model (Colombo et al., 2002), to suppress the alcohol-deprivation effect on drinking (Colombo et al., 2003) and to attenuate cue-induced reinstatement of alcohol seeking behavior (Maccioni et al., 2005). Two groups, File et al. (1991) and Knapp et al. (2007), have found that baclofen counteracts the anxiogenic properties of alcohol consumption-a consequence of alcohol that has been suggested as a possible factor driving consumption (Knapp et al., 2007)

The encouraging preclinical findings with baclofen have led to several clinical trials of baclofen in alcohol dependence. Krupitsky et al. (1993) were the first to report that baclofen may have value for patients with alcohol dependence. They studied 90 individuals with alcohol dependence who had been alcohol free for at least three weeks and who exhibited depression and/or anxiety symptoms. Baclofen $(37.5 \mathrm{mg} / \mathrm{d})$ was compared to placebo, diazepam or amitriptyline. Individuals who received baclofen showed improvement in mood and anxiety comparable to diazepam or amitriptyline and superior to placebo. Drinking outcomes were not reported and the trial was not blind. Addolorato et al (2002) reported the first double-blind trial of $30 \mathrm{mg} / \mathrm{day}$ of baclofen compared to placebo. They found that baclofen was superior to placebo in increasing rates of complete abstinence ( $70 \%$ vs $21 \%$ respectively), and reducing daily drinking levels, anxiety and craving for alcohol in 39 males with alcohol dependence studied over 30 days. Flannery et al. (2004) conducted an open label trial of $30 \mathrm{mg} / \mathrm{d}$ of baclofen in 12 alcohol dependent participants ( 9 males $/ 3$ females) over 12 weeks. Results suggested that baclofen was reasonably tolerated and possibly of value in reducing drinking, craving, and anxiety in alcohol dependent individuals-however, the trial was not placebo-controlled. Finally, in a double-blind, randomized, placebocontrolled trial, Addolorato et al. (2007) reported that baclofen, $30 \mathrm{mg} / \mathrm{d}$, was significantly better than placebo in increasing total abstinence ( $71 \%$ vs. $29 \%$ respectively), decreasing drinking days and reducing craving in 84 individuals (61 males) with alcohol dependence and cirrhosis studied over 12 weeks.

Preliminary work in a small number of patients suggests that baclofen may reduce acute alcohol withdrawal symptoms (Addolorato et al., 2003, 2006) - a property that established pharmacotherapies for alcohol dependence, i.e. naltrexone and acamprosate, have not demonstrated.

Overall, the clinical trials indicate that baclofen shows promise as a pharmacotherapy for alcohol dependence. Furthermore, the effects of baclofen on reducing anxiety and possibly alcohol withdrawal symptoms raise the possibility that baclofen could be particularly useful for patients with these symptoms. 
The current study was designed to further explore the efficacy and tolerability of baclofen in alcohol dependence using a placebo-controlled, randomized trial. The three primary hypotheses were that 1) baclofen-treated individuals would show a significantly greater reduction in heavy drinking days compared to those receiving placebo; 2) the tolerability of baclofen would be acceptable; 3 ) the baclofen group compared to the placebo group would show significantly greater reductions in self-reported craving and anxiety.

\section{Materials and Methods}

\section{Subjects}

Men $(\mathrm{N}=44)$ and women $(\mathrm{N}=36)$ between the ages of 18 and 60 were recruited through newspaper and radio advertisements. The inclusion criteria included: meeting DSM-IV criteria for current alcohol dependence; at least 2 heavy drinking days per week (heavy drinking defined for men as $\geq 5$ standard drinks/day and for women as $\geq 4$ standard drinks/ day) on average during the 4 weeks prior to screening; ability to understand and sign written informed consent; ability to refrain from alcohol for three days prior to the randomization visit. Exclusion criteria included: clinically significant medical disease that might interfere with the evaluation of the study medication or presence of a safety concern (e.g., cirrhosis, kidney impairment, unstable hypertension, diabetes mellitus, seizure disorder); clinically significant psychiatric illness including any psychotic disorder, bipolar disorder, or severe depression; suicidal ideation; concurrent use of any psychotropic medication including antidepressants mood stabilizers, antipsychotics, anxiolytics, stimulants, or hypnotics with the exception that stable doses of antidepressants for two months prior to screening was permitted (6 men and 17 women were on antidepressants); concurrent use of anticonvulsants, insulin, or oral hypoglycemics; aspartate aminotransferase (AST), alanine transaminase (ALT), or gamma-glutamyl transferase (GGT) level $>3$ times the upper limit of normal (ULN), bilirubin > ULN, or serum creatinine > ULN. Additional exclusionary criteria included: positive urine toxicology screen with the exception of cannabis. Individuals with positive cannabis screens were excluded only if they had a history of cannabis dependence. Pregnant women and women of childbearing potential who did not practice a medically acceptable form of birth control (oral or depot contraceptive, or barrier methods such as diaphragm or condom with spermicidal) were excluded as were individuals requiring inpatient treatment or more intense outpatient treatment for their alcohol dependence.

\section{Recruitment, Telephone Screen, and Full Eligibility Screening}

Potential participants were recruited from the Raleigh, Durham, and Chapel Hill area via radio and newspaper advertisements. A preliminary telephone screening was conducted by the study coordinator, and if individuals appeared eligible, they were scheduled for more comprehensive screening. Prior to full screening, individuals read and signed informed consent and were given a copy for their records. A breathalyzer test using an Alco-Sensor III breathalyzer machine (Intoximeters, Inc., St. Louis, MO) was administered [breath alcohol level (BAL) had to be $0.00 \mathrm{gms} / \mathrm{dl}]$. Medical personnel conducted a medical history and examination including a neurological examination. Over-the-counter and prescription medication use was recorded. Laboratory evaluations included complete blood count (CBC) with differential; bilirubin, AST, ALT, GGT, Alkaline Phosphatase, sodium, potassium, chloride, blood urea nitrogen, creatinine, and glucose; and urinalysis and urine toxicology. Women were given a urine pregnancy test (U $\beta-\mathrm{HCG})$ at screening and during treatment weeks 8 and 12. Randomization was implemented stratifying on gender, based on a computerized random number generator where assignment to baclofen or placebo was randomly ordered within gender. Those randomized included 44 men and 36 women. 
Twenty-two men received baclofen and 22 men received placebo; 18 women received baclofen and 18 women received placebo. See Figure 1 for subject flow sheet.

At intake, a detailed psychiatric interview that included the SCID module for alcohol dependence (First et al, 2002) and the Mini International Neuropsychological Inventory (M.I.N.I.), (Sheehan, 1999), was completed. The study coordinator administered the 90-day pretreatment Timeline Followback interview (TLFB),(Sobell et al., 1988), and participants completed the Alcohol Dependence Scale (ADS, Skinner and Allen, 1982), the Zung SelfRating Depression Scale (Zung, 1965), the Spielberger Trait and State Anxiety Inventory (STAI, Speilberger et al., 1969), and the Penn Alcohol Craving Scale (PACS, Flannery et al., 1999). Additionally, participants were asked how many years they had been drinking and completed a short questionnaire concerning their treatment goals (i.e., abstinence, occasional use, or regular but reduced use). Participants were compensated $\$ 10$ for attending each visit to cover travel expenses.

\section{Initial Treatment Visit (study week 0)}

Individuals that met the inclusion criteria and no exclusion criteria were scheduled for the initial treatment visit within 1 week of screening. Eligible individuals were instructed to abstain from drinking alcohol for three days prior to their initial treatment visit. The study coordinator administered a breathalyzer test (BAL had to be $\leq 0.02 \mathrm{gms} / \mathrm{dl}$ at the initial and subsequent visits), conducted the TLFB interview, and asked participants to complete the Zung Depression Scale, STAI, and PACS forms. The study physician evaluated withdrawal symptoms using the Clinical Institute Withdrawal Assessment for Alcohol Revised (CIWAAr, Sullivan et al., 1989), noted the use of medications, and provided a 1-week blister pack of baclofen or placebo with written instructions to titrate dosage. A 1-week back-up blister pack was given in case of delayed appointments or lost doses. Participants also were provided with a calendar style diary to track pill taking, drinking, and any side effects. Finally, participants met with a trained therapist to receive the first of 8 BRENDA therapy sessions (a biopsychosocial approach to evaluate reasons for drinking and techniques to overcome craving and drinking, (Volpicelli, 2001).

\section{Subsequent Treatment Visits}

At study week 1, if participants were tolerating the medication (i.e., had none, very mild, or moderate side effects), they received a 3-week supply of baclofen/placebo. After that, baclofen/placebo was dispensed at study weeks 4 and 8 . The study coordinator collected pill taking, drinking, and side effects diaries and new diaries were distributed at each visit. While baclofen/placebo was dispensed only 4 times during the 3-month period, participants were medically monitored on a weekly (for the 1st month) and biweekly (for the 2nd and 3rd months) basis. Medical monitoring was conducted by study physicians and consisted of taking vital signs, recording use of concomitant medication(s), and in-depth side effect monitoring using an Adverse Events Form that included common baclofen side effects (e.g., drowsiness, sedation, fatigue). At each visit, participants also were given a breathalyzer test (BAC had to be $\leq 0.02 \mathrm{gms} / \mathrm{dl}$ ), the TLFB interview, and complete the Zung, STAI, and PACS. At week 4, blood was drawn for evaluation of liver functioning; at week 12 or early termination, a physical was conducted along with urinalysis Additional 30-minute BRENDA sessions were conducted at each visit. Participants were encouraged to attend Alcoholics Anonymous (AA) during treatment.

Participants who wished to continue treatment at the conclusion of the study were offered outpatient counseling and medication through the UNC Alcohol and Substance Abuse Program. 


\section{Adverse Events Monitoring}

In describing adverse events, standard terminology was employed. All adverse events were categorized and rated on a 5-point scale of severity from very mild to very severe using an Adverse Events Reporting form and Adverse Events Instructions, which provided descriptions of severity ratings and medication reduction and stopping rules. Adverse events, including serious adverse events, were closely followed; if indicated, dose reductions or discontinuation of medication was made. All individuals who experienced adverse events were monitored until a return to their baseline state was achieved.

Primary Outcome-The percent of heavy drinking days was the primary efficacy outcome.

\section{Statistical Analyses}

Study participants were first characterized on baseline demographic variables (age, gender, education, etc.), alcohol dependence severity (ADS), drinking history variables (e.g., years of alcohol use, prior treatments), pretreatment drinking frequency and quantity (TLFB), craving, and scores on measures of state and trait anxiety and depression. (PACS, STAI, Zung). These variables were summarized by calculating means, and standard deviations for each treatment group. An independent sample t-test was used to assess group differences for continuous variables. Nominal variables were analyzed via chi-square tests of independence.

All inferential analyses included all participants that are randomized (intent-to-treat). Primary outcome measures were the proportion of heavy drinking days (\%HDD) and the proportion of abstinence (\%ABS), which were summarized from the TLFB data. Keselman et al. (1998) discuss that very often researchers fail to inspect the validity of the assumptions for the statistical model they are using. A key assumption for the general linear model (GLM) analytical framework applied to continuous outcomes such as \%HDD and \%ABS, is normality of the outcome measure. Prior to conducting any analysis, inspection of all outcome measures was conducted, resulting in deviations from normality for both \%HDD and $\% \mathrm{ABS}$. The square-root transformation normalized both outcome measures.

In addition to the summary scores from the above measures, we implemented the generalized estimating equations (GEE, Hedeker and Gibbons, 2006) approach, which accommodated the daily repeated measures data and accounts for within-subject correlations. As missing data are inevitable, we implemented pattern-mixture models (Hedeker and Gibbons, 2006) to assess whether important estimates were dependent on missing data patterns, and to provide overall estimates of effects by averaging over the various missing-data patterns. As implemented by the SAS Proc Genmod procedure, the GEE approach offers consistent parameter estimates and accommodates covariates.

We examined time to events outcomes, survival curves, which were estimated using the Cox Proportional Hazards Model. As is typically done, patients lost to follow-up were treated as censored observations, as were patients who never achieved the event of interest. Survival models were implemented in SAS with the procedure PROC PHREG (Allison, 1995).

Psychiatric, craving and weekly usage measures were analyzed via a general mixed model approach that examined change from screening to the average of the post-screening assessments. In order to accomplish this, we used PROC MIXED in SAS (Hedker and Gibbons, 2006) and examined average outcome over the medication phase, rather than assuming a linear change over time. Unlike standard repeated measures ANOVA, this approach permits flexibility in the assumptions made about the covariance structure of the multiple assessments. We specified a toeplitz structure, which assumes that assessments 
made closer together in time may not be correlated in the same way as assessments separated by longer time intervals. A likelihood ratio test revealed that this covariance structure fits better compared to two more commonly used covariance structures: the compound symmetry and first-order autoregressive covariance structures ( $p<0.05$ for both).

A moderator is a baseline measure or prerandomization characteristic that has a differential effect on outcome across intervention condition (Kraemer et al., 2002). Moderators are typically defined as variables that significantly interact with condition. We examined psychiatric and craving scales as potential moderators of drug effects.

\section{Results}

\section{Demographics and Pre-Treatment Measures}

Demographic information on the 80 study participants ( 40 placebo and 40 baclofen) is provided in Table 1 along with pre-treatment related drinking information and pre-treatment scores on craving, state and trait anxiety, and self-reported depression scales. Some minor differences were present between the placebo and baclofen groups but, overall, the groups were quite similar.

\section{Percent Heavy Drinking Days}

A significant time effect was found $(\mathrm{p}<0.001)$ but no significant baclofen effect was detected $(\mathrm{t}(73)=0.59, \mathrm{p}=0.56)$ for $\% \mathrm{HDD}$ during treatment where on-average rates were $25.5 \%( \pm 23.6 \%)$ for placebo and $25.9 \%( \pm 23.2 \%)$ for baclofen. Incorporating the repeated measures through the GEE analysis, indicated a non-significant difference between placebo and baclofen $(\mathrm{Chi}(1)=0.12, \mathrm{p}=0.73)$, where on-aveage baclofen had $19.3 \%$ occurrence of heavy usage (19.3\%) compared to $24.7 \%$ for placebo across the medication period. This is further confirmed by focusing on the weekly behavior as illustrated in Figure 2, where across each of the 12 weeks of the medication period there is no difference between groups $(\mathrm{F}(1,73)=0.01, \mathrm{p}=0.98)$.

\section{Percent Abstinent Days}

A marginal effect for time was found $(\mathrm{t}(76)=1.87, \mathrm{p}=0.07$ and no significant baclofen effect was detected $(\mathrm{t}(73)=0.53, \mathrm{p}=0.50)$ for $\% \mathrm{ABS}$ during treatment where on-average rates were $50.6 \%( \pm 25.9 \%)$ for placebo and $49.9 \%( \pm 27.9 \%)$ for baclofen.. Incorporating the repeated measures, indicated a nonsignificant difference between placebo and baclofen $(\mathrm{Chi}(1)=0.27$, $\mathrm{p}=0.61$ ), where on-average baclofen had a $51.7 \%$ occurrences of abstinence compared to $51.6 \%$ for placebo across the medication period. Similar results are seen by focusing on the average weekly behavior as illustrated in Figure 3, where across each of the 12 weeks of the medication period there is no difference between groups $(\mathrm{F}(1,73)=0.06, \mathrm{p}=0.81)$.

\section{Effect of Baclofen on Craving, Anxiety, and Depression}

General mixed model results indicated no significant differences between placebo and baclofen patients for craving (13.5 \pm 6.3 vs $11.6 \pm 5.9$ respectively, $(F(1,74)=2.40, p=0.13)$, depression $(30.5 \pm 12.8$ vs. $27.8 \pm 13.0,(\mathrm{~F}(1,74)=2.80, \mathrm{p}=0.10)$, or trait anxiety $(32.8 \pm 14.6$ vs.30.0 $\pm 14.3,(\mathrm{~F}(1,72)=2.19, \mathrm{p}=0.14)$ looking at on average outcome post screening adjusted for the screening assessment. In the statistical contrast of state anxiety, we found a significant difference in on-average severity $(\mathrm{F}(1,73)=5.39, \mathrm{p}=0.02)$ where estimated means were $32.2 \pm 16.7$ for placebo and $27.5 \pm 13.5$ for baclofen indicating a possible baclofen effect on reducing anxiety levels (See Figure 4). 


\section{Time to Usage analyses}

To further examine possible effects of baclofen, we tested standard time to analyses: (a) time to first usage, (b) time to first heavy usage, (c) time to two consecutive abstinences, and (d) time to two consecutive heavy usages. For time to first usage, as illustrated in Figure 5, we saw no difference between baclofen and placebo $(\operatorname{Chi}(1)=2.26, \mathrm{p}=0.13)$ where the hazard ratio (HR) was 0.695 , indicating the rate of first usage for baclofen was $30.5 \%$ slower compared to placebo. For time to first heavy usage or relapse, as illustrated in Figure 6, we saw no difference between baclofen and placebo $(\mathrm{Chi}(1)=0.09, \mathrm{p}=0.76)$, where HR $=0.924$, indicating a $7.6 \%$ slower rate to first heavy usage for BAC compared to PBO. For time to two consecutive abstinences, as illustrated in Figure 7, we saw a marginal difference between baclofen and placebo $(\operatorname{Chi}(1)=3.25, \mathrm{p}=0.07)$, where $\mathrm{HR}=1.571$, indicating a $57.1 \%$ faster rate to two consecutive abstinences for BAC compared to PBO. For time to two consecutive heavy usages, we saw no difference between baclofen and placebo $(\operatorname{Chi}(1)=0.36, \mathrm{p}=0.55)$, where $\mathrm{HR}=0.851$, indicating a $14.9 \%$ slower rate to two consecutive heavy usages for BAC compared to PBO.

\section{Analysis of Potential Moderator of Usage: Gender}

Following NIH guidelines, we a priori planned to investigate the role of gender on outcome. For $\%$ HDD and $\%$ ABS, we found no evidence of treatment differences acting differentially dependent on Gender $(\mathrm{F}(1,71)=, 0.01, \mathrm{p}=0.91$ for $\% \mathrm{HDD} ; \mathrm{F}(1,71)=0.85, \mathrm{p}=0.36$ for $\% \mathrm{ABS})$. For the time to analyses we see non-significant interactive effect for gender: $\operatorname{Chi}(1)=0.05, \mathrm{p}=0.84$ for time to first usage; $\operatorname{Chi}(1)=0.005, \mathrm{p}=0.94$ for time to first heavy usage; $\operatorname{Chi}(1)=0.01, \mathrm{p}=0.92$ for two consecutive abstinences; $\operatorname{Chi}(1)=0.003, \mathrm{p}=0.96$ for two consecutive heavy usage.

\section{Analysis of Potential Moderator of Usage: Craving, Depression, and Anxiety}

For $\% \mathrm{HDD}$ and $\% \mathrm{ABS}$, we found no evidence of treatment differences acting differentially dependent on craving $(\mathrm{F}(1,71)=, 0.01, \mathrm{p}=0.97$ for \%HDD; $\mathrm{F}(1,71)=0.56, \mathrm{p}=0.46$ for $\% \mathrm{ABS})$, depression, $(\mathrm{F}(1,69)=, 0.06, \mathrm{p}=0.81$ for $\% \mathrm{HDD} ; \mathrm{F}(1,69)=0.24, \mathrm{p}=0.63$ for $\% \mathrm{ABS})$, state anxiety $((\mathrm{F}(1,70)=, 0.06, \mathrm{p}=0.80$ for $\% \mathrm{HDD} ; \mathrm{F}(1,70)=0.11, \mathrm{p}=0.74$ for $\% \mathrm{ABS})$, or trait anxiety $((\mathrm{F}(1,69)=, 0.32, \mathrm{p}=0.57$ for \%HDD; $\mathrm{F}(1,69)=0.05, \mathrm{p}=0.83$ for \%ABS $))$.

No moderating effects for any of these variables were evident on the time to analyses.

\section{Analysis of Missing Data}

To determine whether the lack of significance among treatments was driven by missing data, we classified three monotonic patterns of patients' available data (patients with data up to week 8 , between week 8 and week 12 , and data beyond week 12, the expected endpoint) and assessed the interaction of pattern with treatment was differed using our primary analyses. The pattern-mixture results were non-significant for total percentage heavy usage $(F(2,69)=0.32, p=0.73)$ and total percentage abstinence $(\mathrm{F}(2,69)=2.82, \mathrm{p}=0.07)$. Similarly for the GEE model, the pattern mixture results were non-significant for heavy usage $(\operatorname{Chi}(1)=4.65, \mathrm{p}=0.10)$ and abstinence $(\mathrm{Chi}(1)=1.67, \mathrm{p}=0.43)$.

\section{Safety, Tolerability, and Pill Compliance}

Pill compliance was comparable between the two groups. Compliance ranged from 71.6\%-96.4\% for placebo patients and 47.8\%-94.9\% for the medication patients. Statistical contrasts were all non-significant $(\mathrm{p}>0.28)$. Adverse events were relatively mild. Only two adverse events affected more than $5 \%$ of the sample, which were drowsiness $(10 \%$ within PBO (4/40) versus $28 \%$ within baclofen (11/40)) and headaches (10\% within placebo (4/40) versus $3 \%$ within baclofen (1/40)). Fisher's exact methods indicated a non-significant 
contrast between placebo and baclofen in the prevalence of drowsiness $(\mathrm{p}=0.08)$ and prevalence of headaches $(\mathrm{p}=0.36)$. Of the placebo patients $80 \%(32 / 40)$ completed treatment versus $70 \%$ (28/40) within baclofen, which was not statistically different $(\mathrm{p}=0.44)$. Of the reasons for termination, three patients reported reasons attributable to the medication, with one patient reporting desire to drop due to fatigue and mood swings, a second reporting a desire to drop because received medication was not the wonder drug she or he anticipated receiving, and a third reported a desire to drop due to severe tendonitis. All three patients were assigned to baclofen.

\section{Discussion}

The search for efficacious and safe medications for the treatment of alcohol dependence remains a key goal of treatment research. The discoveries that naltrexone and acamprosate are effective for alcohol dependence were major breakthroughs in the clinical management of alcohol dependence and have broadened the awareness of the role of pharmacotherapy for alcohol dependence. However, the overall effectiveness of naltrexone and acamprosate are modest (Kranzler and Van Kirk, 2001) leading to efforts to find additional and possibly more effective medications.

Baclofen has emerged as a medication of potential interest for the treatment of alcohol dependence. The preclinical evidence, as reviewed in the Introduction, supports the hypothesis that baclofen reduces alcohol intake, reduces the reinforcing and motivational properties of alcohol, and prevents some of the neurobehavioral consequences of alcohol consumption such as induction of anxiety. The neuropharmacological basis of these actions is not fully understood but activation of $\mathrm{GABA}_{\mathrm{B}}$ receptors by baclofen counteracts the ventral tegmental-nucleus accumbens dopamine response to alcohol (see Maccioni et al., 2009) and has other complex actions on various neurotransmitter systems of relevance to alcohol (see Knapp et al., 2007).

Clinical trials, to date, have been limited with only 123 individuals studied in two placebocontrolled, randomized trials (Addolorato et al., 2002; 2007). Nevertheless, these two trials are of considerable interest as they show a significant advantage of baclofen over placebo in enhancing abstinence and reducing drinking quantities and reducing anxiety and craving. Given the preclinical and early clinical evidence, the current trial was designed to further test the hypothesis that baclofen has efficacy for alcohol dependence.

The current trial did not find evidence for efficacy of baclofen for alcohol dependence on the primary outcome measure of \%Heavy Drinking Days though a highly significant overall treatment effect was found indicating that participation in the trial itself was efficacious in reducing heavy drinking. Additionally, no effect of baclofen was noted on the secondary outcomes of \%Days Abstinent or craving for alcohol. A modest baclofen effect on levels of state anxiety was found. Furthermore, evaluation by gender did not reveal evidence for any differential response to baclofen by gender. Finally, examining baclofen response by baseline levels of craving for alcohol or levels of anxiety found that neither high levels of craving nor high levels of anxiety were associated with response to baclofen. These data do not support the hypothesis that baclofen has efficacy for alcohol dependence; however, this work must be considered in the context of the overall clinical trial evidence with particular attention to variations across trials.

Clinical trials in alcohol dependence are well known to exhibit great variability that are thought to be related to the myriad of factors that affect outcome in alcohol dependent patients. Noteworthy examples of this variation include the failure of the large Veterans' Administration trial to demonstrate efficacy of naltrexone (Krystal et al, 2001) despite the 
overall evidence that naltrexone is effective (Kranzler and Van Kirk, 2001) and the two large trials of acamprosate in the United States that failed to show efficacy (Anton et al., 2006; Mason et al., 2006) when, again, the preponderance of evidence shows that acamprosate is efficacious (Kranzler and Van Kirk, 2001). Kiefer and Mann (2006), commenting about the patient population and design of the COMBINE trial have highlighted the fact that patients in the U.S. COMBINE trial appeared to have relatively low levels of physical dependence and that this may have impacted the response to a medication such as acamprosate which may be more effective in the presence of physical dependence. This factor may be relevant to understanding differences in the current trial compared to the positive Addolorato trials of baclofen (2002; 2007). The Addolorato trials recruited patients with alcohol dependence who presented to an alcohol treatment unit whereas individuals in the current trial were recruited from advertising. This difference in recruitment was likely a key factor as to why the participants in the Italian trials, compared to the U.S. trial, drank nearly twice the amount of drinks/drinking day (10.7 (placebo)/17.6 (baclofen) vs. 6.9 (placebo)/7.3 (baclofen) respectively), had higher levels of withdrawal symptoms, and uniformly had a goal of abstinence. This indicates the Italian study population had more severe dependency characteristics than the U.S. population and a different treatment goal. Therefore, though it is not established that baclofen would have greater efficacy in more highly dependent patients, this hypothesis should be investigated.

It is of interest that baclofen did significantly reduce anxiety in the current trial similar to what Addolorato et al. (2002) reported. However, no relationship between baseline levels of anxiety and response to baclofen were detected. Given the high rates of anxiety symptoms in alcohol dependence it would be of considerable clinical value to have a medication that could reduce anxiety, reduce alcohol use, did not have addiction liability and did not have dangerous interactions with alcohol. Preclinical work has shown that $\mathrm{GABA}_{\mathrm{B}}$ systems are involved in anxiety behavior and that activation of the $\mathrm{GABA}_{\mathrm{B}}$ receptor either by baclofen or by positive allosteric modulators of the receptor is anxiolytic (Cryan and Kaupmann, 2005). Furthermore, baclofen counteracts the anxiogenic effects of alcohol in an animal model (Knapp et al., 2007). Additionally, the addiction liability of baclofen appears low and laboratory investigation of baclofen at $40 \mathrm{mg}$ and $80 \mathrm{mg}$ doses combined with intoxicating levels of alcohol indicate a reasonable safety profile when baclofen is combined with alcohol (Evans and Bisaga, 2009). Therefore, whereas there does appear to be a signal that baclofen may have anxiolytic effects in patients with alcohol dependence, the clinical impact of this remains ambiguous.

Subjective craving for alcohol as measured by the PACS or Obsessive Compulsive Drinking Scale (OCDS) (Anton et al., 1995) has been shown to predict drinking outcomes in clinical trials (Flannery et al., 2003). Addolorato et al. (2002; 2007) found that baclofen reduced craving for alcohol as measured by the OCDS significantly more than placebo. This is of interest as it suggests that baclofen might reduce drinking behavior through an effect on craving for alcohol. In the current trial, we did not find that baclofen reduced craving more than placebo and individuals with high baseline craving for alcohol did not show a baclofen effect. Therefore, based on the present study, the effect of baclofen on craving for alcohol is not clear.

Overall, our failure to find significant efficacy for baclofen despite the promising preclinical data and two positive placebo-controlled clinical trials raises two other important points. First, there is the question of whether a $30 \mathrm{mg} / \mathrm{d}$ dose of baclofen is an adequate dose for most patients and second, can a baclofen-responsive patient be identified?

With regards to dose, the clinical trials to date have used a baclofen dose of $30 \mathrm{mg} /$ day--in the low therapeutic range for muscle spasticity but anticipated to have fewer side effects, an 
important consideration for early clinical trials. However, there are case studies that suggest that larger doses of baclofen may be required for efficacy in some individuals. Ameisen (2005), a physician, self-prescribed baclofen by titrating from $30 \mathrm{mg} /$ day to $270 \mathrm{mg} /$ day and then reducing the dose to $120 \mathrm{mg} /$ day due to somnolence. He reported suppression of alcohol consumption and a profound reduction in anxiety and craving. Buchman (2006) described a patient with alcohol dependence who had failed naltrexone, acamprosate, and topiramate but who had marked improvement in alcohol consumption associated with a sense of relaxation at a dose of 100-140 mg/day of baclofen. These cases are noteworthy because they raise the possibility of a meaningful dose-response relationship for baclofen as a treatment for alcohol dependence and that $30 \mathrm{mg}$ of baclofen may be an insufficient dose for some patients. Dose-response studies to examine the efficacy and safety of higher doses of baclofen in alcohol dependence are clearly needed.

The question of a baclofen-responsive patient is another issue that deserves attention. The heterogeneity of alcohol dependence and the great variability in response across individuals in clinical trials in alcohol dependence speaks to the likelihood that there are individual characteristics associated with a positive response to specific pharmacotherapies. The best example here may be the emerging evidence that polymorphisms within the $\mu$-opioid receptor gene predict naltrexone response (see Oroszi et al., 2009). To date, no prospective studies have examined any putative characteristic that might identify a baclofen-responsive patient. Based on some of the preclinical and clinical trial data one could postulate that symptoms such as high anxiety or high levels of alcohol withdrawal symptoms could be predictors though we did not find evidence that anxiety symptoms were predictive in the current trial. Here again, prospective clinical trials are needed.

With regards to tolerability, the current trial found that baclofen was generally well tolerated. Importantly, no serious adverse events were reported and, despite ongoing alcohol consumption by many individuals, no evidence for significant alcohol/baclofen interactions was observed. This is consistent with the recent laboratory study of Evans and Bisaga (2009) which also failed to show significant safety concerns when intoxicating levels of alcohol were consumed in the presence of baclofen. More individuals receiving baclofen did experience sedation than placebo in keeping with this known side-effect of baclofen, but, overall, this was benign. These findings suggest that trials with higher doses of baclofen in an alcohol dependent population are feasible based on tolerability.

In summary, the current trial did not find evidence that baclofen at a dose of $10 \mathrm{mg}$ three times per day was superior to placebo in the treatment of alcohol dependence. No baclofen effect was found on heavy drinking or abstinent days. The presence of high levels of anxiety or high craving was not associated with a baclofen response though there was some evidence that baclofen has anxiolytic effects. Given the heterogeneity of alcohol dependence and the fact that Addolorato et al. $(2002 ; 2007)$ have reported a therapeutic benefit to baclofen in alcoholism, it cannot be concluded that baclofen has no value in the pharmacotherapy of alcohol dependence. Additional clinical trials examining dose and controlling for individual patient characteristics are needed to better understand the role of baclofen and $\mathrm{GABA}_{\mathrm{B}}$ agonists in general as possible pharmacotherapies for alcohol dependence.

\section{Acknowledgments}

This work was supported by National Institute of Alcohol Abuse and Alcoholism Grant R21 AA015392 and by GCRC Grant RR00046 and CTSA grant UL1RR025747 from the National Institutes of Health. The authors wish to dedicate this paper to the memory of Dr. Barbara Flannery whose persistence and dedication led to the completion of this study. 


\section{References}

Addolorato G, Leggio L, Abenavoli L, Agabio R, Caputo F, Capristo E, Colombo G, Gessa GL, Gasbarrini G. Baclofen in the treatment of alcohol withdrawal syndrome: a comparative study vs diazepam. Am J Med. 2006; 119:276.e13-8. [PubMed: 16490478]

Addolorato G, Caputo F, Capristo E, Colombo G, Gessa GL, Gasbarrini G. Ability of baclofen in reducing alcohol craving and intake: II--Preliminary clinical evidence. Alcohol Clin Exp Res. 2000; 24:67-71. [PubMed: 10656195]

Addolorato G, Leggio L, Abenavoli L, DeLorenzi G, Parente A, Caputo F, Janiri L, Capristo E, Rapaccini GL, Gasbarrini G. Suppression of alcohol delirium tremens by baclofen administration: a case report. Clin Neuropharmacol. 2003; 26:258-262. [PubMed: 14520166]

Addolorato G, Caputo F, Capristo E, Domenicali M, Bernardi M, Janiri L, Agabio R, Colombo G, Gessa GL, Gasbarrini G. Baclofen efficacy in reducing alcohol craving and intake: a preliminary double-blind randomized controlled study. Alcohol Alcohol. 2002; 37:504-508. [PubMed: 12217947]

Addolorato G, Leggio L, Ferrulli A, Cardone S, Vonghia L, Mirijello A, Abenavoli L, D'Angelo C, Caputo F, Zambon A, Haber PS, Gasbarrini G. Effectiveness and safety of baclofen for maintenance of alcohol abstinence in alcohol-dependent patients with liver cirrhosis: randomised, double-blind controlled study. Lancet. 2007; 370:1915-1922. [PubMed: 18068515]

Allison, PD. Survival Analysis Using the SAS System: A Practical Guide. SAS Institute Inc; Cary NC: 1995.

Ameisen O. Case Report. Complete and prolonged suppression of symptoms and consequences of alcohol dependence using high-dose baclofen: A self-case report of a physician. Alcohol Alcohol. 2005; 40:147-150. [PubMed: 15596425]

Anton RF, O'Malley SS, Ciraulo DA, Cisler RA, Couper D, Donovan DM, Gastfriend DR, Hosking JD, Johnson BA, LoCastro JS, Longabaugh R, Mason BJ, Mattson ME, Miller WR, Pettinati HM, Randall CL, Swift R, Weiss RD, Williams LD, Zweben A, COMBINE Study Research Group. Combined pharmacotherapies and behavioral interventions for alcohol dependence: the COMBINE study: a randomized controlled trial. JAMA. 2006; 295:2003-2017. [PubMed: 16670409]

Anton RF, Moak DH, Latham P. The Obsessive Compulsive Drinking Scale: a self-rated instrument for the quantification of thoughts about alcohol and drinking behavior. Alcohol Clin Exp Res. 1995; 19:92-99. [PubMed: 7771669]

Bucknam W. Case Report: Suppression of alcohol dependence and craving using high-dose baclofen. Alcohol Alcoholism. 2007; 42:158-160.

Colombo G, Serra S, Brunetti G, Atzori G, Pani M, Vacca G, Addolorato G, Froestl W, Carai MAM, Gessa GL. The GABAB receptor agonists baclofen and CGP 44532 prevent acquisition of alcohol drinking behaviour in alcohol-preferring rats. Alcohol Alcohol. 2002; 37:499-503. [PubMed: 12217946]

Colombo G, Serra S, Brunetti G, Vacca G, Carai MAM, Gessa GL. Suppression by baclofen of alcohol deprivation effect in Sardinian alcohol-preferring (sP) rats. Drug Alcohol Depend. 2003; 70:105108. [PubMed: 12681531]

Cryan JF, Kaupmann K. Don't worry 'B' happy!: a role for GABA(B) receptors in anxiety and depression. Trends Pharmacol Sci. 2005; 26:36-43. [PubMed: 15629203]

Daoust M, Saligaut C, Lhuintre JP, Moore N, Flipo JL, Boismare F. GABA transmission, but not benzodiazepine receptor stimulation, modulates ethanol intake by rats. Alcohol. 1987; 4:469-472. [PubMed: 2829943]

Evans SM, Bisaga A. Acute interaction of baclofen in combination with alcohol in heavy social drinkers. Alcohol Clin Exp Res. 2009; 33:19-30. [PubMed: 18840257]

File SE, Zharkovsky A, Gulati K. Effects of baclofen and nitrendipine on ethanol withdrawal responses in the rat. Neuropharmacology. 1991; 30:183-190. [PubMed: 2030822]

First, MB.; Spitzer, RL.; Gibbon, M.; Williams, JBW. Structured Clinical Interview for DSM-IV-TR Axis I Disorders, Research Version, Patient Edition. Biometrics Research, New York State Psychiatric Institute; (SCID-I/P) New York: 2002. 
Flannery BA, Garbutt JC, Cody MW, Renn W, Grace K, Osborne M, Crosby K, Morreale M, Trivette A. Baclofen for alcohol dependence: a preliminary open-label study. Alcohol Clin Exp Res. 2004; 28:1517-1523. [PubMed: 15597084]

Flannery BA, Volpicelli JR, Pettinati HM. Psychometric properties of the Penn Alcohol Craving Scale. Alcohol Clin Exp Res. 1999; 23:1289-1295. [PubMed: 10470970]

Flannery BA, Poole SA, Gallop RJ, Volpicelli JR. Alcohol craving predicts drinking during treatment: an analysis of three assessment instruments. J Stud Alcohol. 2003; 64:120-126. [PubMed: 12608492]

Hedeker, D.; Gibbons, RD. Longitudinal Data Analysis. John Wiley \& Sons, Inc.; Hoboken, NJ: 2006.

Keselman HJ, Algina J, Kowalchuk RK, Wolfinger RD. A comparison of two approaches for selecting covariance structures in the analysis of repeated measurements. Communications in Statistics Simulations and Computation. 1998; 27:591-604.

Knapp DJ, Overstreet DH, Breese GR. Baclofen blocks expression and sensitization of anxiety-like behavior in an animal model of repeated stress and ethanol withdrawal. Alcohol Clin Exp Res. 2007; 31:582-595. [PubMed: 17374037]

Kraemer HC, Wilson GT, Fairburn CG, Agras WS. Mediators and moderators of treatment effects in randomized clinical trials. Arch Gen Psychiatry. 2002; 59:877-883. [PubMed: 12365874]

Kranzler HR, Van Kirk J. Efficacy of naltrexone and acamprosate for alcoholism treatment: a metaanalysis. Alcohol Clin Exp Res. 2001; 25:1335-1341. [PubMed: 11584154]

Krupitsky EM, Burakov AM, Ivanov VB, Krandashova GF, Lapin IP, Grinenko AJa, Borodkin YuS. Baclofen administration for the treatment of affective disorders in alcoholic patients. Drug Alcohol Depend. 1993; 33:157-163. [PubMed: 8261880]

Krystal JH, Cramer JA, Krol WF, Kirk GF, Rosenheck RA, Veterans Affairs Naltrexone Cooperative Study 425 Group. Naltrexone in the treatment of alcohol dependence. N Engl J Med. 2001; 345:1734-1739. [PubMed: 11742047]

Maccioni P, Serra S, Vacca G, Orru A, Pes D, Agabio R, Addolorato G, Carai M, Gessa G, Colombo G. Baclofen-induced reduction of alcohol reinforcement in alcohol-preferring rats. Alcohol. 2005; 36:161-168. [PubMed: 16377457]

Kiefer F, Mann K. Pharmacotherapy and behavioral intervention for alcohol dependence. JAMA. 2006; 296:1727-1728. [PubMed: 17032980]

Mason BJ, Goodman AM, Chabac S, Lehert P. Effect of oral acamprosate on abstinence in patients with alcohol dependence in a double-blind, placebo-controlled trial: the role of patient motivation. J Psychiatr Res. 2006; 40:383-393. [PubMed: 16546214]

Oroszi G, Anton RF, O’Malley S, Swift R, Pettinati H, Couper D, Yuan Q, Goldman D. OPRM1 Asn40Asp predicts response to naltrexone treatment: a haplotype-based approach. Alcohol Clin Exp Res. 2009; 33:383-393. [PubMed: 19053977]

Sheehan, D.; Janavs, J.; Baker, R.; Harnett-Sheehan, K.; Knapp, E.; Sheenan, M. Mini International Neuropsychiatric Interview (M.I.N.I.). University of South Florida; Tampa: 1999.

Skinner, HA.; Horn, JL. Alcohol Dependence Scale (ADS) user's guide. Addiction Research Foundation; Toronto: 1984.

Speilberger, CD.; Gorsuch, RL.; Lushene, RE. The state trait anxiety inventory manual. Consulting Psychologists Press; Palo Alto: 1969.

Sobell LC, Sobell MB, Leo GL, Cancilla A. Reliability of a timeline followback method: Assessing normal drinkers' reports of recent drinking and a comparative evaluation across several populations. Br J Addict. 1988; 83:393-402. [PubMed: 3395719]

Sullivan JT, Sykora K, Schneiderman J, Naranjo CA, Sellers EM. Assessment of alcohol withdrawal: The revised Clinical Institute Withdrawal Assessment of Alcohol Scale (CIWA-Ar). Br J Addict. 1989; 84:1353-1357. [PubMed: 2597811]

Volpicelli, JR.; Pettinati, HM.; McLellan, AT.; O'Brien, CP. Combining medication and psychosocial treatments for addictions: The BRENDA method. Guilford Press; New York: 2001.

Walker BM, Koob GF. The gamma-aminobutyric acid-B receptor agonist baclofen attenuates responding for ethanol in ethanol-dependent rats. Alcohol Clin Exp Res. 2007; 31:11-18. [PubMed: 17207096] 
Zung WW. A self-rating depression scale. Arch Gen Psychiatry. 1965; 12:63-70. [PubMed: 14221692] 
Figure 1.

Trial Flow Diagram. LTF (lost to follow-up). 


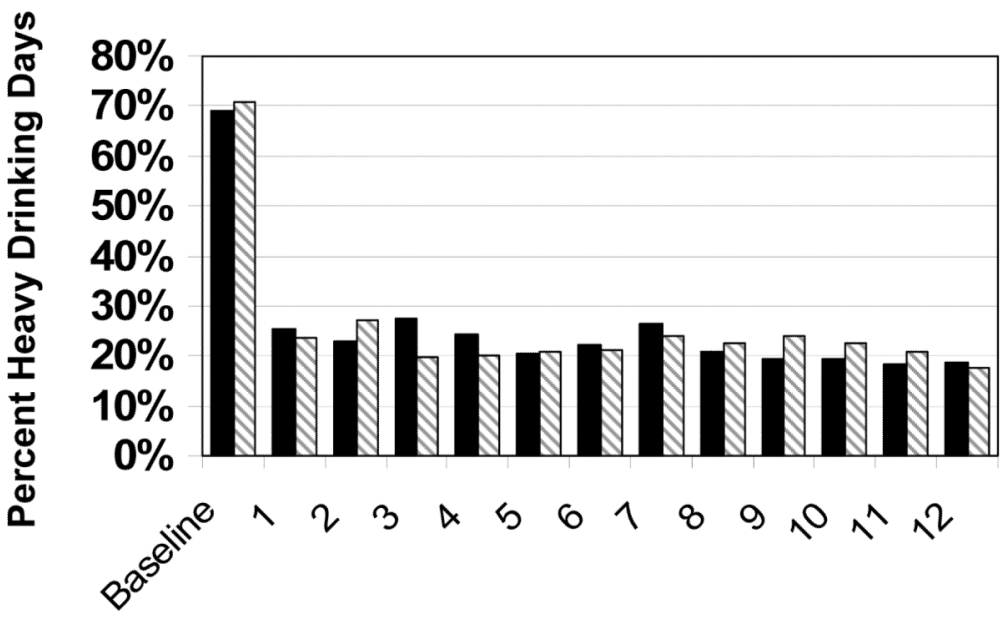

Weeks of Treatment

- PBO $\triangle \mathrm{BAC}$

Figure 2.

Percent Heavy Drinking Days Over time 


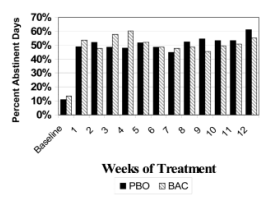

Figure 3.

Percent Abstinent Days over Time 


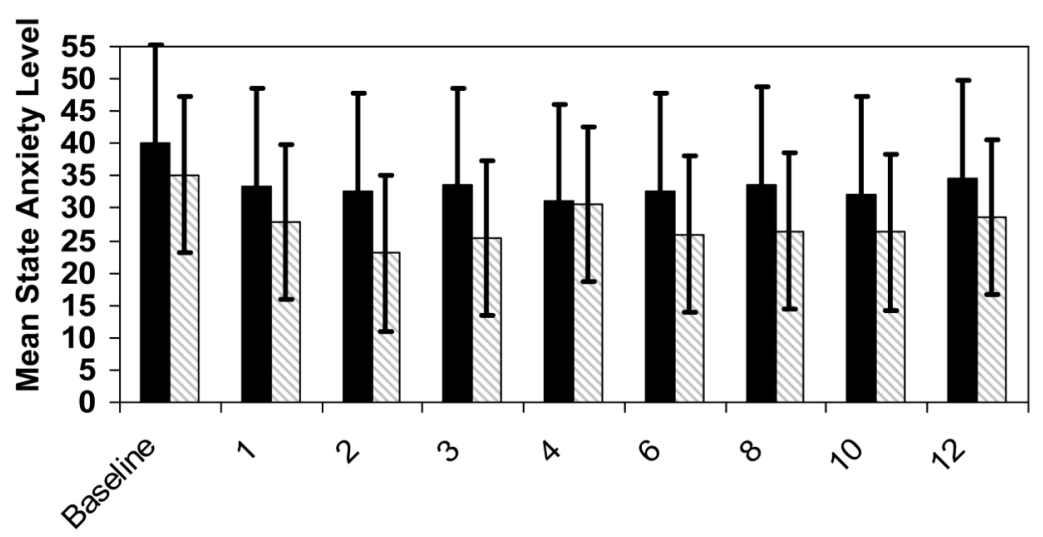

\section{Weeks in Treatment}

\section{- Placebo $\square$ Baclofen}

Figure 4.

Mean State Anxiety over Time 


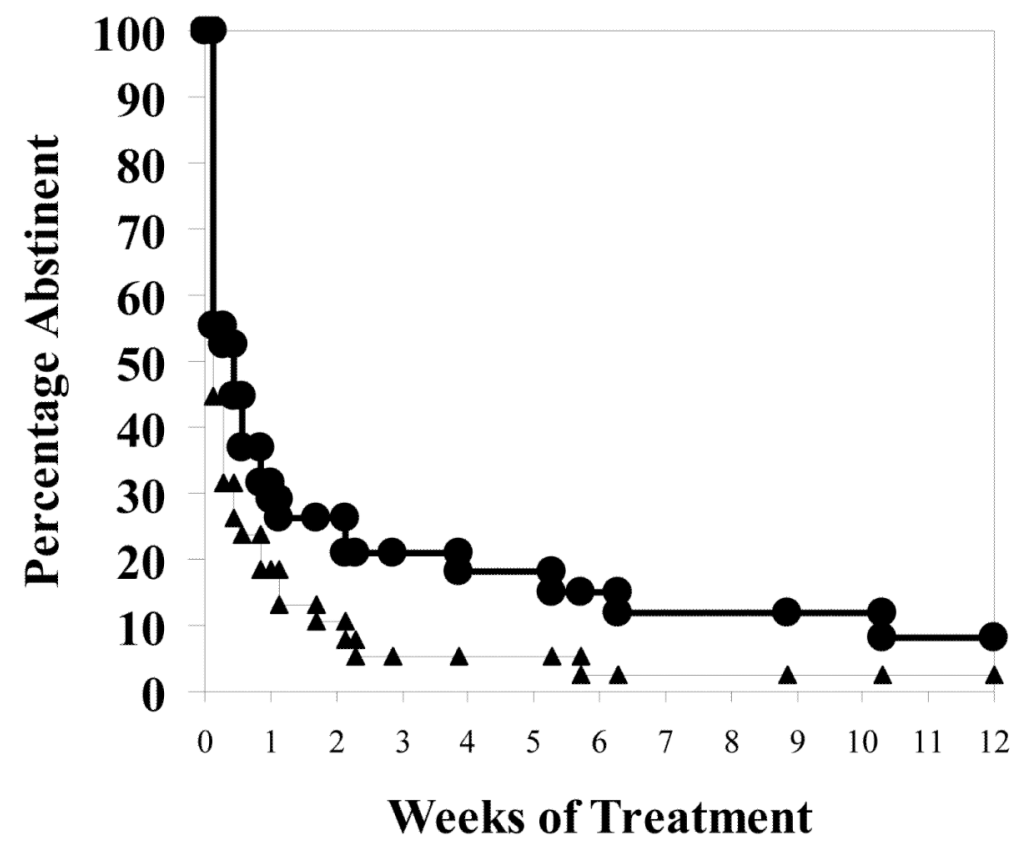

Figure 5.

Percent Abstinent 


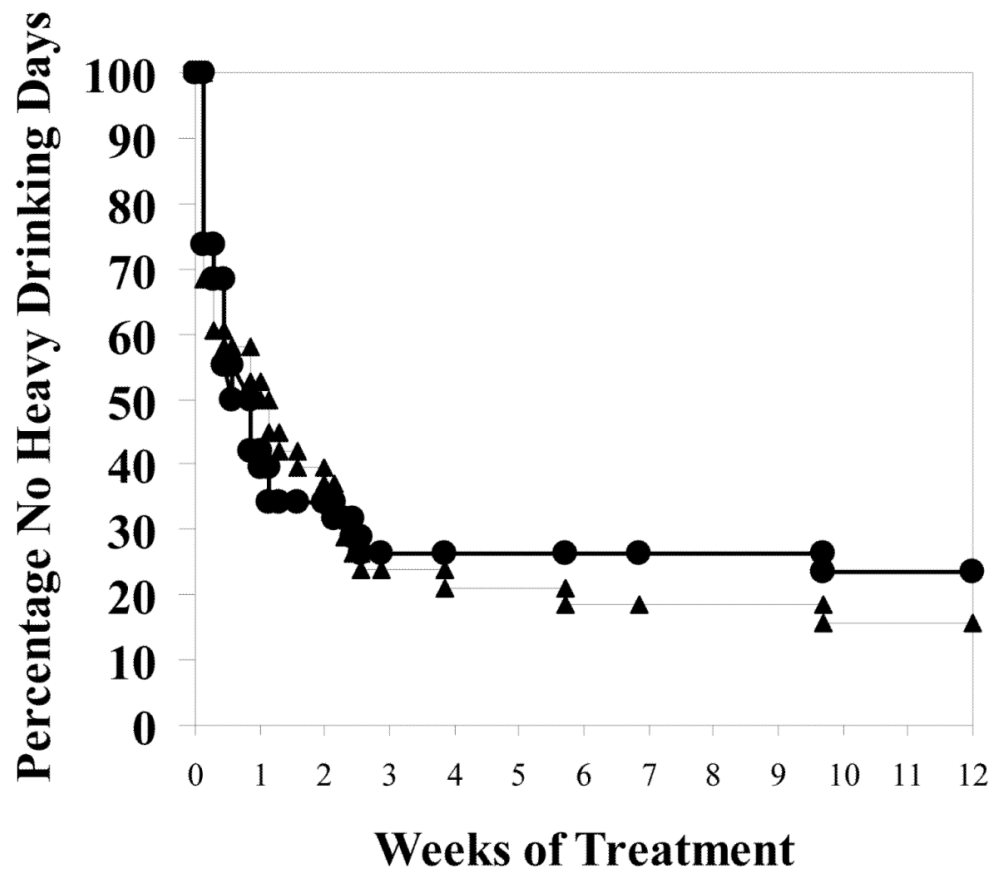

$\triangle \mathrm{PBO} \longrightarrow \mathrm{BAC}$

Figure 6.

Percent with Return to Heavy Drinking 


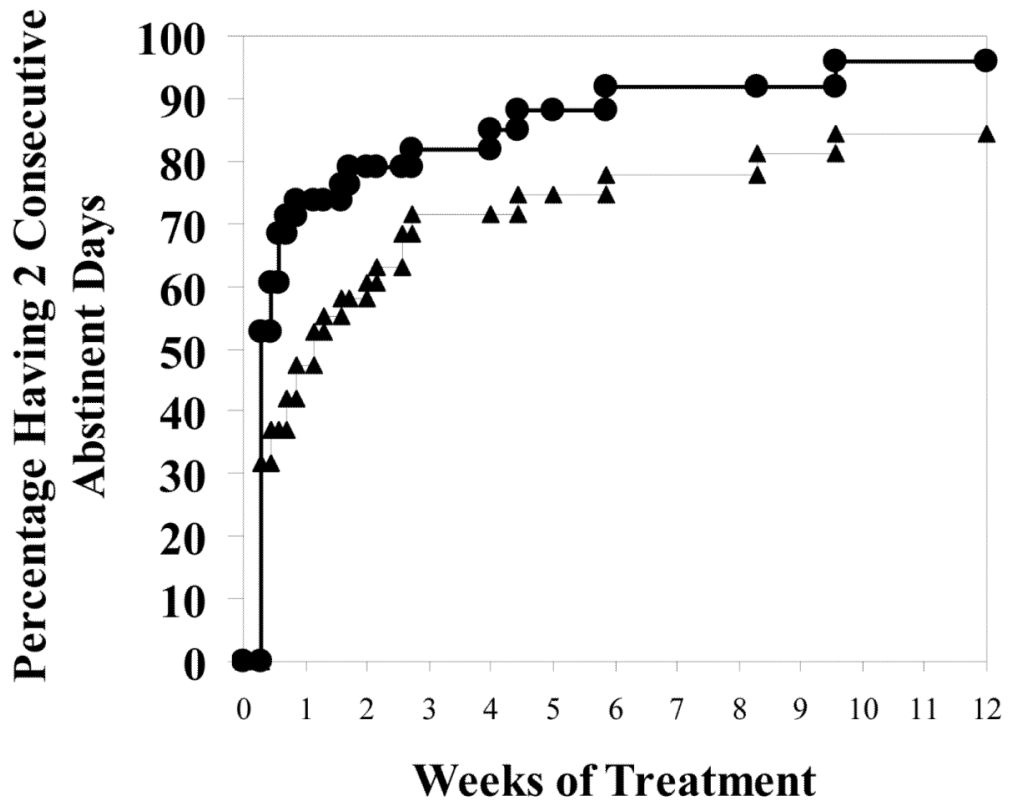

Figure 7.

Percent with Two Consecutive Abstinent Days 
Table 1

Demographics and Pre-Treatment Variables

\begin{tabular}{|c|c|c|c|}
\hline & Placebo $(\mathrm{N}=40)$ & Baclofen $(\mathrm{N}=40)$ & Significance \\
\hline Age & $50.3( \pm 7.2)$ & $47.5( \pm 7.6)$ & $\mathrm{ns}$ \\
\hline Gender & $22 \mathrm{M} / 18 \mathrm{~F}$ & $22 \mathrm{M} / 18 \mathrm{~F}$ & $\mathrm{~ns}$ \\
\hline Married & $64 \%$ & $50 \%$ & $\mathrm{~ns}$ \\
\hline Race/Ethnicity & $97 \%$ white & $95 \%$ white & $\mathrm{ns}$ \\
\hline Education: College degree & $37 \%$ & $32 \%$ & $\mathrm{~ns}$ \\
\hline Pre Tx CIWA-Ar score & $2.1( \pm 2.4)$ & $2.7( \pm 2.7)$ & $\mathrm{ns}$ \\
\hline ADS score $\max =47$ & $13.1( \pm 5.3)$ & $11.7( \pm 5.8)$ & ns \\
\hline Age Onset Alc Depend & $35.4( \pm 15.1)$ & $33.5( \pm 10.5)$ & $\mathrm{ns}$ \\
\hline Years Alcohol Use & $27.9( \pm 9.9)$ & $23.5( \pm 99)$ & $\mathrm{ns}$ \\
\hline $\begin{array}{l}\text { Treatment Goal: } \\
\text { abstinence } \\
\text { occasional use } \\
\text { regular but reduced use }\end{array}$ & $\begin{array}{l}16 \% \\
46 \% \\
38 \%\end{array}$ & $\begin{array}{l}32 \% \\
45 \% \\
23 \%\end{array}$ & $\mathrm{~ns}$ \\
\hline Prior Treatments: none & $65 \%$ & $53 \%$ & ns \\
\hline$\% \mathrm{HDD}$ & $69.0( \pm 25.2)$ & $71.0( \pm 28.1)$ & $\mathrm{ns}$ \\
\hline$\%$ ABST & $10.9( \pm 14.3)$ & $13.5( \pm 18.6)$ & $\mathrm{ns}$ \\
\hline Drinks/Drinking Day & $6.9( \pm 3.2)$ & $7.3( \pm 3.7)$ & $\mathrm{ns}$ \\
\hline PACS (Craving), $\max =30$ & $16.4( \pm 5.6)$ & $14.4( \pm 5.8)$ & $\mathrm{ns}$ \\
\hline $\begin{array}{l}\text { Zung Depression }(\max = \\
80)\end{array}$ & $37.0( \pm 10.5)$ & $35.4( \pm 8.1)$ & $\mathrm{ns}$ \\
\hline $\begin{array}{l}\text { Speilberger State Anxiety } \\
\max =80\end{array}$ & $38.5( \pm 12.7)$ & $34.1( \pm 10.8)$ & $\mathrm{ns}$ \\
\hline $\begin{array}{l}\text { Speilberger Trait Anxiety } \\
\max =80\end{array}$ & $42.1( \pm 11.4)$ & $38.3( \pm 8.7)$ & $\mathrm{ns}$ \\
\hline
\end{tabular}

